\title{
Regulatory Gene Network Pathway among Brain Cancer and Associated Disease: a Computational Analysis
}

\author{
Sayed Asaduzzaman 1,2,* (D), Rana Chakma ${ }^{1(\mathbb{D})}$, Hasin Rehana ${ }^{3,4}(\mathbb{D}$, M. Raihan $5(\mathbb{D}$ \\ 1 Department of Computer Science and Engineering, Rangamati Science and Technology University, Vedvedi, Rangamati, \\ Bangladesh \\ 2 Department of Information and Communication Technology, Mawlana Bhashani Science and Technology University, \\ Tangail-1902, Bangladesh \\ 3 Department of Computer Science and Engineering, Rajshahi University Engineering and Technology, Rajshahi, \\ Bangladesh \\ 4 Department of Computer Science and Engineering, Daffodil International University, Dhanmondi, Dhaka, Bangladesh \\ 5 Department of Computer Science and Engineering, North Western University, Khulna, Bangladesh \\ * Correspondence: asadcse.rmstu@gmail.com, s.asaduzzaman@rmstu.ac.bd;
}

Abstract: Brain cancer (BC), melanoma (ML), bladder cancer (BDC), benign tumor (BT), gliomas $(\mathrm{GM})$ are annihilating diseases among people because of their high death risk. These five diseases are associated among themselves. The analysis shows that there are eight common genes TERT, MYC, GSTP1, GSTM1, CXCR4, CXCL12, GSTT1, PROM1, among those associated with five diseases. Preprocessing has been done to find these eight common genes based on biological, biochemical, and genetic relationships between common genes. This analysis identifies the most significant hub proteins. Seed, nodes, and edges create networks that indicate the relationship between the genes and proteins. Protein-protein interaction (PPIs) network, TF -gene interactions, gene regulatory network (GRN), protein-drug, protein-chemical, gene-diseases analysis has been done the common genes and their interactions, correlation, association, and candidate drugs. Topological analysis finally provides eight common genes that can develop an efficient drug design for this research.

Keywords: bioinformatics; topological properties analysis; gene regulatory network; protein-drug interaction; brain cancer; melanoma; benign tumor.

Abbreviations: $\mathrm{BC}=$ Brain Cancer; $\mathrm{ML}=$ Melanoma; $\mathrm{BDC}=$ Bladder Cancer; $\mathrm{BT}=$ Benign Tumor $\mathrm{GM}=$ Gliomas.

(C) 2021 by the authors. This article is an open-access article distributed under the terms and conditions of the Creative Commons Attribution (CC BY) license (https://creativecommons.org/licenses/by/4.0/).

\section{Introduction}

Nowadays, cancer is the most significant disease among deadly diseases in the world. Among them, brain cancer is one of the most common cancers, causing death for many people. Brain tumors are different in terms of shape, texture, size, and location (Neuroma, Meningioma, Pituitary, Glioma, etc.). An enhanced deep learning model has been used to classify and detect brain cancer from MRI images using a deep learning algorithm in [1]. In Asia, brain cancer/brain tumor and problem in central nervous system-related diseases are very frequent, according to a report of WHO, 2018. According to deep learning, highlights among the relationship between brain cancer and other brain disorders like stroke, Alzheimer's, Parkinson's, and Wilson's disease, leukoaraiosis, and other neurological disorders has been shown in [2]. Potential fatal skin malignancy is called melanoma, and it is increasing day by 
day. Age, gender, family history, genetics are some of the risk factors for melanomaenvironmental risks, like sun exposure, influence melanoma [3,4]. Progress from primary to metastatic disease for genetically evolving of uveal melanomas continues [5].

About 170000 deaths are happening every year worldwide due to the deadly disease of bladder cancer. Muscle invasive bladder cancer and advanced bladder cancer treatment have been represented by V. G. Patel in [6]. In [7], urinary bladder cancer and its worldwide risk factors have been represented. According to the research, age, gender, region are some of the significant factors for bladder cancer. W. J. A. Witlox et al. investigated and performed an analysis to reveal the association between the Mediterranean diet and bladder cancer [3748]. Age, gender, TNM stages, smoking status, MDS are some of the risk factors for bladder cancer. In [9], ambient air pollution and bladder cancer have no clear evidence for their association. The risk of benign tumor in myotonic dystrophy type I (DM1) has been compared in [10]. The significant risk factors like skin, endocrine, sex, tumor status are shown in the study. An artificial neural network (ANN) is used to assess benign tumor risk in terms of sensitivity, ROC, CI, specificity, PPV, etc [11]. P-value in the research shows the significant risk factors in the benign tumor. Gliomas have a complex relationship with the central nervous system and is a deadly disease in recent years. To evade the immune system, gliomas employ several mechanisms [12]. In [13], characteristics between diabetes and lungs are correlated and is also shown the correlation among the diseases. These diseases can be connected through the common parameters among them. Several studies have been carried out for disease risk factor detection using machine learning and statistical analysis in [14-16]. Besides, gene analysis has been done in [17] using online tools and revealed significant gene network

In this research, the riskiest five diseases $(\mathrm{BC}=$ brain cancer, $\mathrm{ML}=$ melanoma, $\mathrm{BDC}$ =bladder cancer, $\mathrm{BT}=$ benign tumor, $\mathrm{GM}=$ Gliomas) and their common 8 genes have been found by mining. The network between the eight genes has been analyzed by the most popular online gene analysis tools to reveal and illustrate the PPI, GRN, TF-Gene Interaction, and protein-drug and protein-chemical interactions.

\section{Materials and Methods}

String analysis, Protein-Protein Interaction Network, Pathway analysis, regulatory gene network analysis are carried out on the common genes of 5 diseases (BC, ML, BDC, BT, GM). All genes were mined from the online platform NCBI (https://www.ncbi.nlm.nih.gov/gene/) gene database.

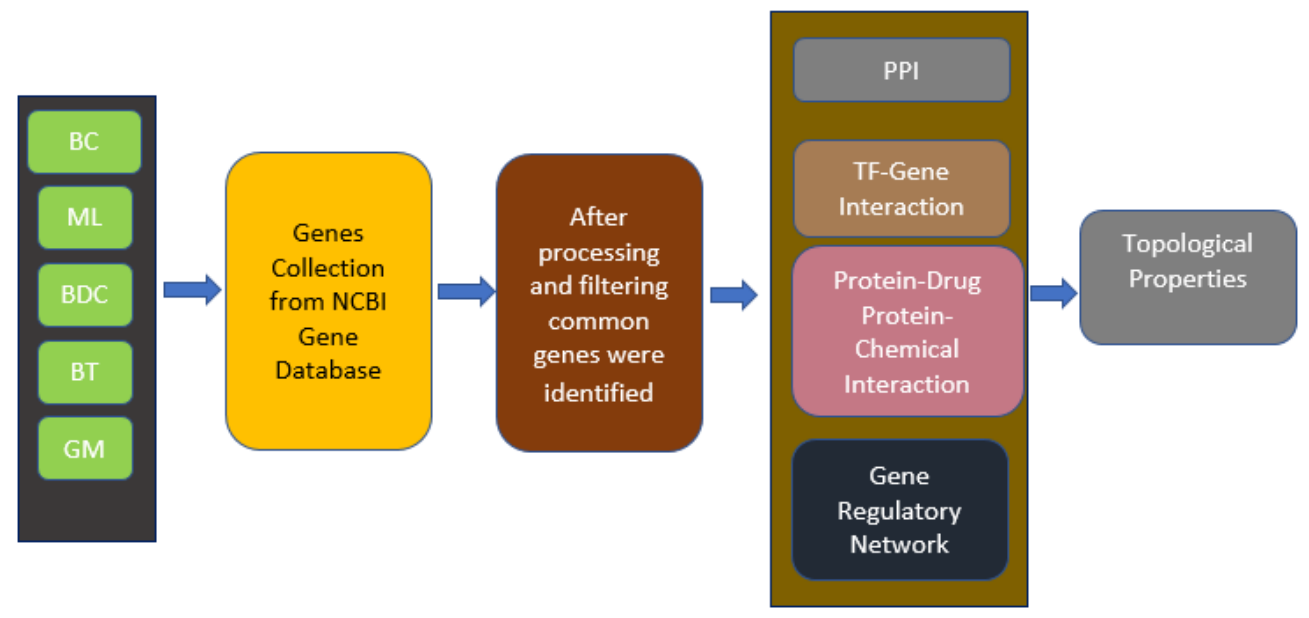

Figure 1. Flowchart of the proposed research methodology. 
The common genes among the three diseases were explored using Rstudio (https://rstudio.com/). The common genes were given as input in NetworkAnalyst (https://www.networkanalyst.ca/) and (https://www.omicsnet.ca/) to examine their overview. The use of essential bioinformatics tools helps to understand a drug candidate better. Figure 1 exhibits the aimed inquired research methodology.

\subsection{Gene collection.}

All genes were collected from the NCBI's online gene database (https://www.ncbi.nlm.nih.gov/gene/). In this research, Table 1 shows the number of genes for all species and Homo sapiens. The genes of Homo sapiens have been extracted using $\mathrm{R}$ Programming. The 8 most common genes were found TERT (ID: 7015) MYC (ID: 4609), GSTP1 (ID: 2950), GSTM1 (ID: 2944), CXCR4 (ID: 7852), CXCL12 (ID: 6387), GSTT1 (ID: 2952), PROM1 (ID: 8842).

Table 1. Gene collection comparison for all species vs Homo sapiens.

\begin{tabular}{l|l|l} 
Name of Disease & Genes for All Species & Genes for Homo sapiens \\
\hline Brain Cancer (BC) & 31 & 30 \\
\hline Melanoma (ML) & 13123 & 1940 \\
\hline Bladder Cancer (BDC) & 2135 & 1243 \\
\hline Benign Tumor (BT) & 793 & 740 \\
\hline Gliomas (GM) & 743 & 669
\end{tabular}

\subsection{Gene co-expression network and pathway analysis.}

Gene co-expression and pathway analysis have been done using an online analysis tool (www.genemania.org). Here all the analysis has been shown by interaction lines of different colors.

\subsection{Protein-protein interaction (PPI).}

Generic protein-protein interaction network has been analyzed using String Interactome database. Here analysis was done using a gene analysis website (www.omicsnet.ca).

\subsection{Gene regulatory network (GRN).}

Gene regulatory network has been carried out by the famous network analysis website (www.NetworkAnalyst.ca). Here database was used Signor 2.0. Gene-miRNA and signaling networks have been done for the regulatory network analysis.

\subsection{Protein-chemical and protein-drug interaction.}

Protein-chemical and protein-drug analysis was done to find out possible drug design. For protein-chemical analysis, Comparative Toxicogenesis Database and Protein Disease analysis DrugBank database have been considered. A website (www.NetworkAnalyst.ca), was used for these analyses.

\subsection{Gene-disease interaction and tissue-specific co-expression.}

For gene-disease interaction, the DisGeNET database has been used. For gene coexpression network, the Immuno-Navigator database was used along with Whole Blood cell. 
Two famous gene network analysis online tools (www.NetworkAnalyst.ca) and (www.omicsnet.ca) has been applied.

\subsection{String analysis.}

String analysis was done using online string analysis tools (www.string-db.org) and research tool Cytoscape V 3.8.2. K-means clustering applied on the whole network for 8 common genes. The glass ball effect of string shows the protein.

\section{Results and Discussion}

Detailed results and discussion of the associated disease have been presented in this section.

\subsection{Co-expression network and physical interaction pathway.}

A co-expression network is an undirected graph that can be used for finding the interaction among the significant genes. The common 8 genes found among the associated five diseases are interconnected with more than 20 genes. Figure 2 shows that there are physical interactions $54.31 \%$, predicted $21.4 \%$, co-expression $11.23 \%$, shared protein domain $5.79 \%$, colocalization $3.80 \%$, pathway $3.39 \%$ among the related genes.

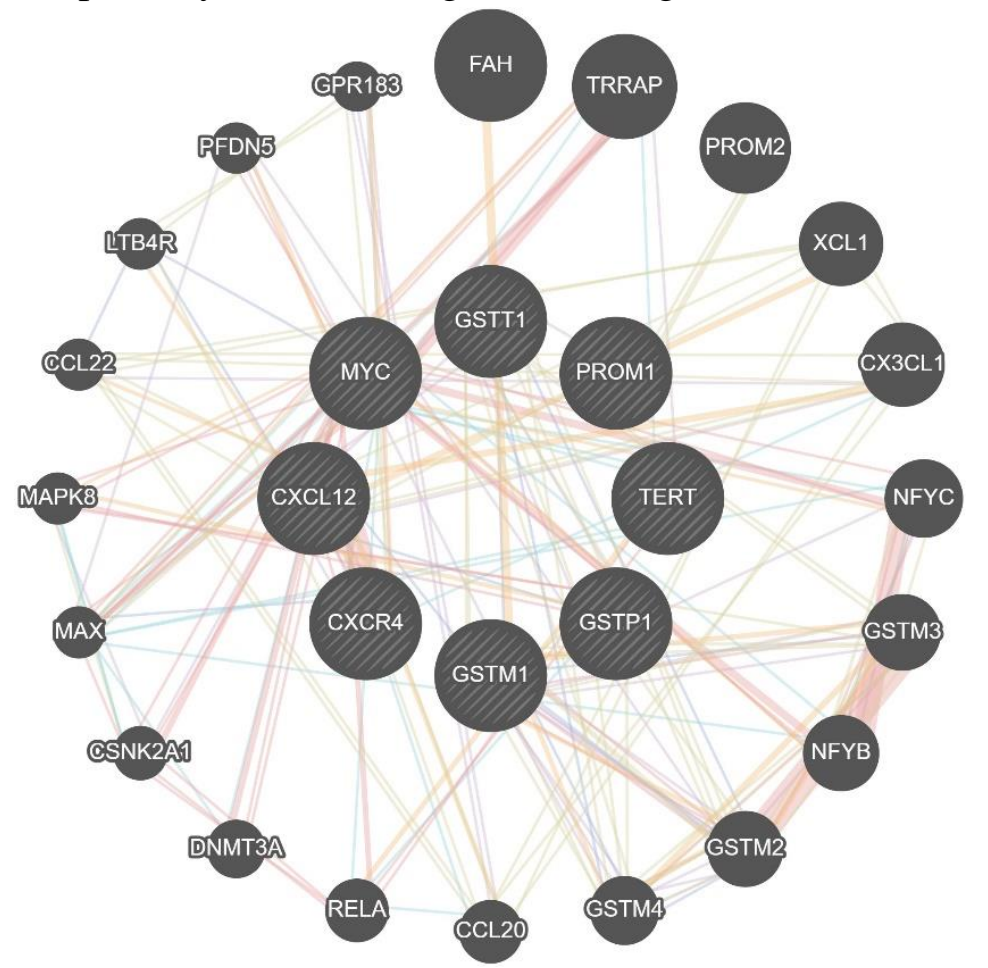

Figure 2. Gene co-expression network and pathway among 8 common genes using GeneMania.

\subsection{TF-gene interaction.}

TF-gene interactions have been shown in Figure 3. Green highlighted nodes are seed nodes and red nodes are edges that represent the interactions of TF- Gene. TRRUST database was used, and the TF-gene interactions were constructed using text mining followed by manual curation. 


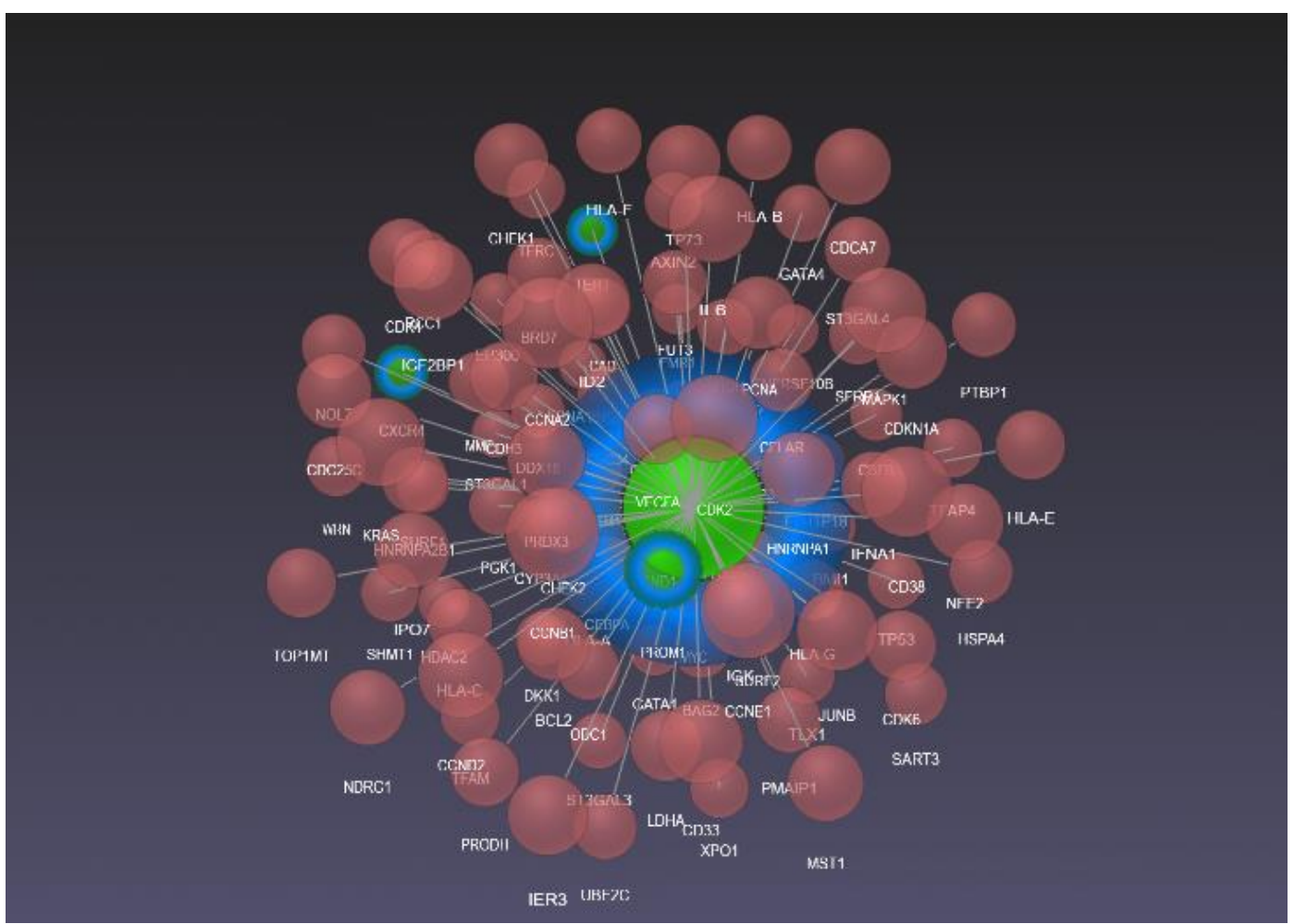

Figure 3. TF-Gene Interaction among the common gene.

\subsection{Protein-protein interaction (PPI).}

Protein-protein interaction among the common genes has been represented in Figure 4. Here there are 7 seed nodes, 873 edges, and 823 nodes. IMEX Interactome database has been used to extract the information.

\subsection{Gene regulatory network (GRN).}

Gene regulatory network provides molecular functions based on biological activities. In this research, GRN has been analyzed in two ways. Gene-miRNA and signaling network analysis have been shown in Figure 5 and Figure 6, respectively. Gene-miRNA network uses miRTar Base database, and the network has 6 seeds 208 nodes, and 200 edges. Signaling network uses SIGNOR database, and 6 seeds nodes 127 nodes and 126 edges are in the network. Blue nodes are protein nodes, and yellow nodes are chemicals, orange and red nodes are proteins and protein families.

\subsection{Protein-drug protein-chemical interaction.}

Figure 7, Figure 8, and Figure 9 illustrate the protein-drug interactions which use DrugBank Database. Three subnetworks have been created where the seed is protein, and other nodes are drugs. Sub-networks contains 2 seeds, 21 edges, 21 edges (Subnetwork1), 1 seed 3 edges 4 nodes (Subnetwork 2), 1 seed 3 edges 4 nodes (Subnetwork 3), respectively. Protein chemical interactions have been depicted in Figure 10 where 8 seeds, 1308 edges, 828 nodes. Seed nodes are proteins, and other nodes are chemicals. CTD (Comparative Toxic genomics) database has been used here. 


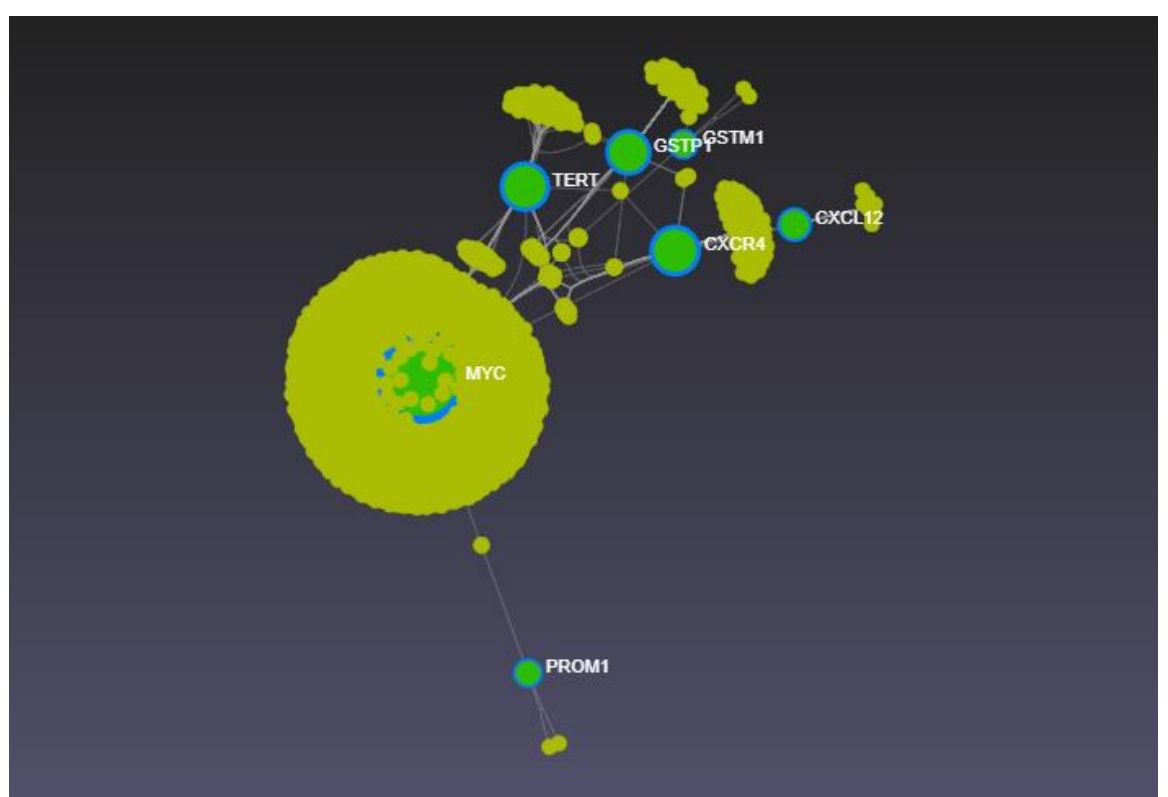

Figure 4. Protein-protein interaction network.

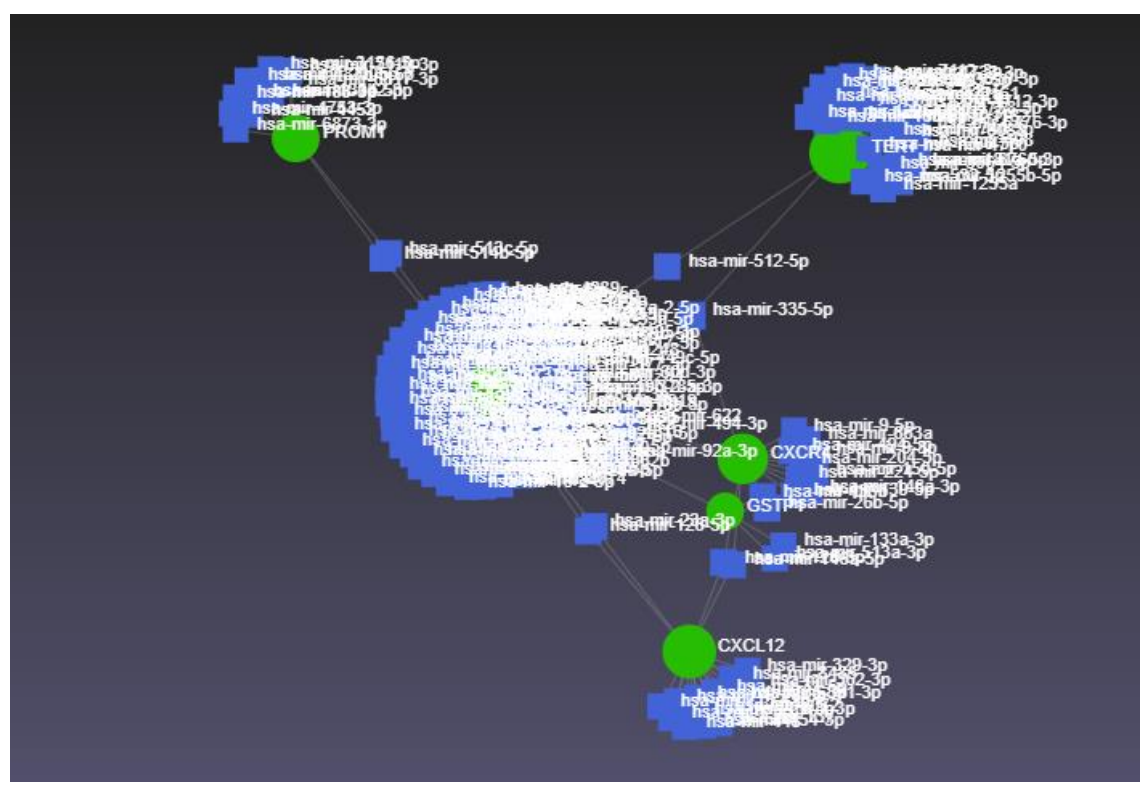

Figure 5. Gene-miRNA interaction network.

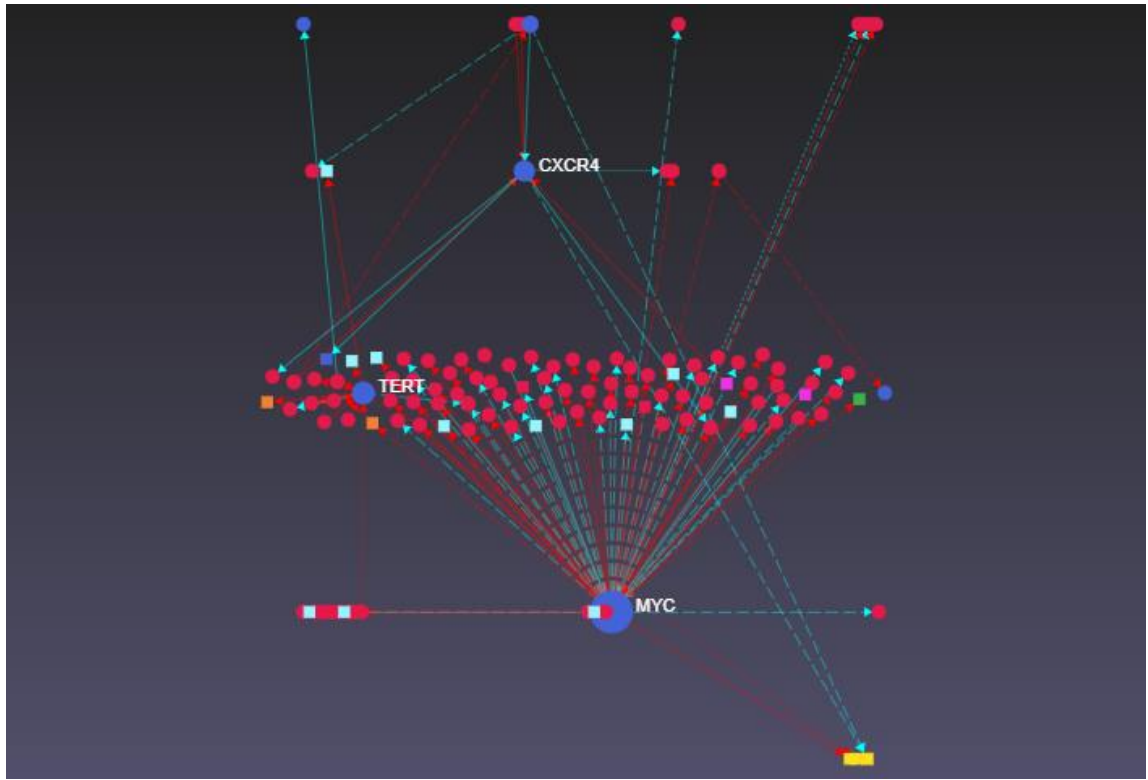

Figure 6. Gene regulatory signaling network. 


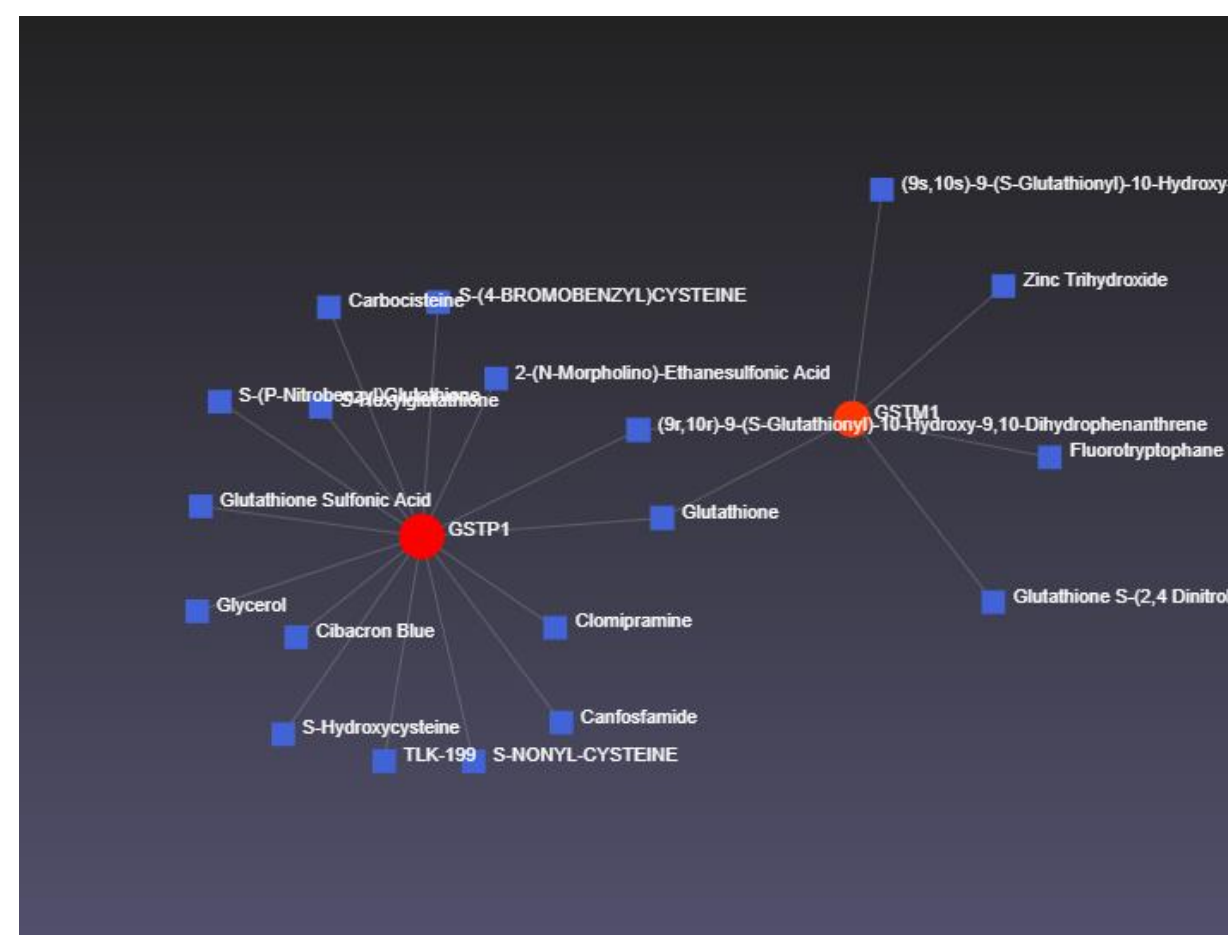

Figure 7. Protein-drug interaction subnetwork 1.

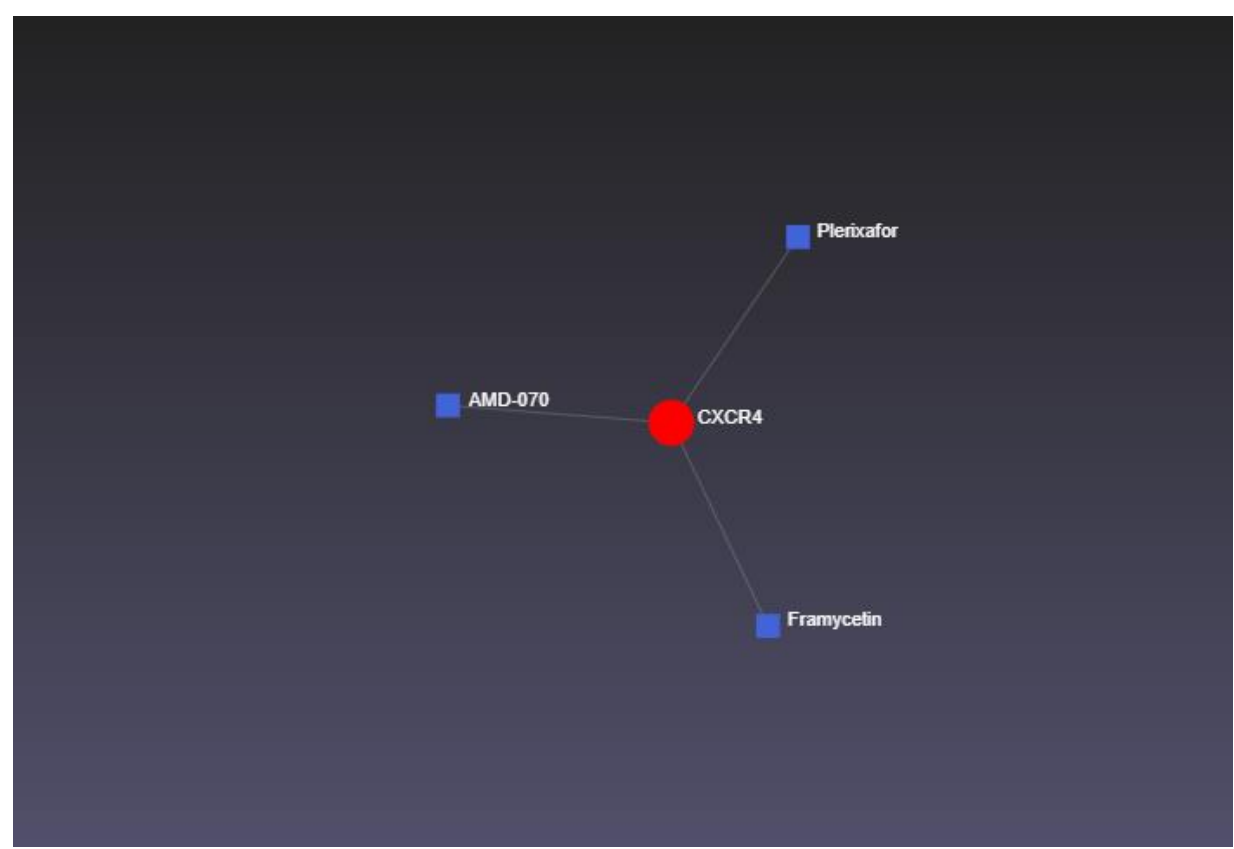

Figure 8. Protein-drug interaction subnetwork 2.

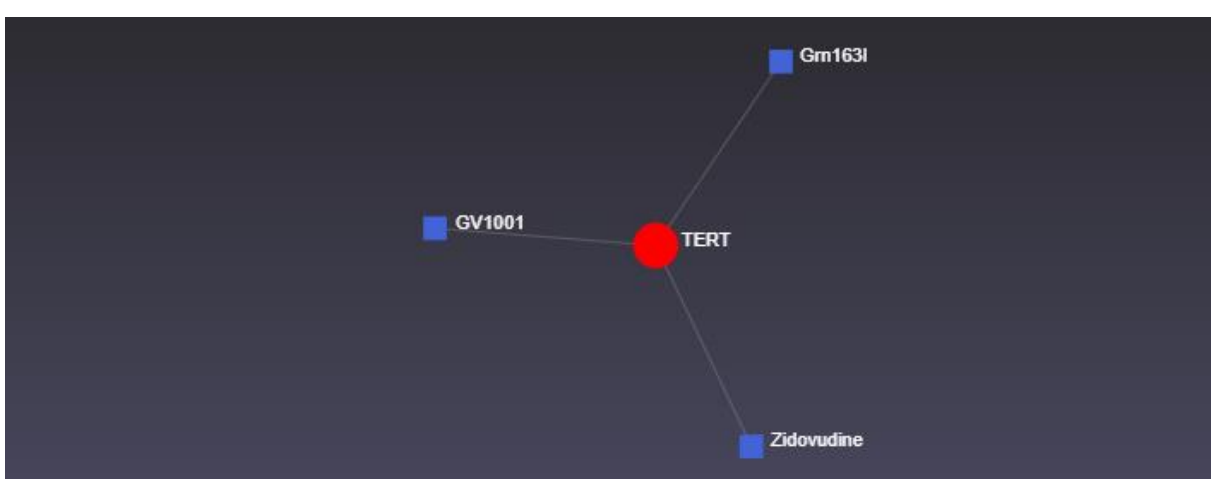

Figure 9. Protein-drug interaction subnetwork 3. 


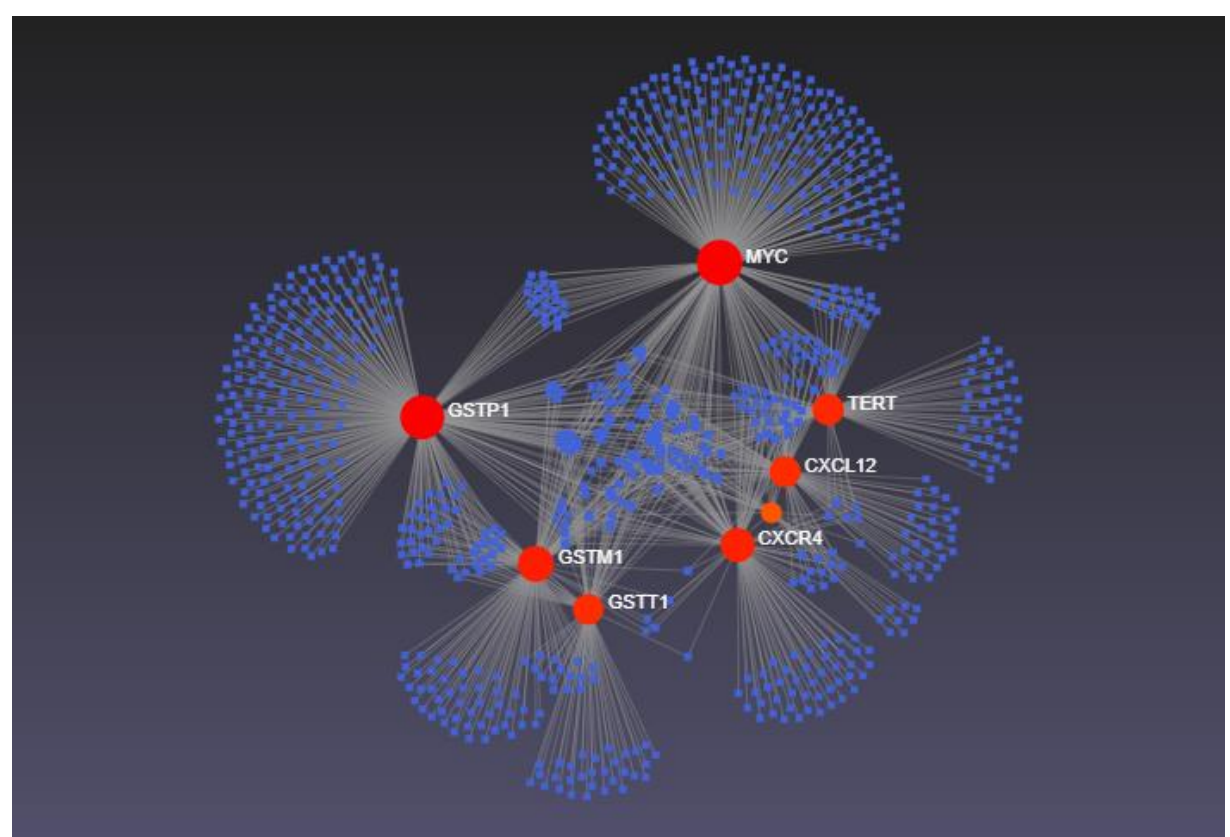

Figure 10. Protein-chemical interaction network.

\subsection{Gene-disease association.}

Gene disease association has been shown in Figure 11. Two subnetworks have been shown: Figure 11 with 2 seeds 56 nodes 54 edges, and Figure 12 with 1 seed 2 nodes and 3 edges. DisGeNET database has been used to extract the data of genes.

\subsection{Tissue-specific co-expression network.}

Figure 13 and Figure 14 show the two subnetworks of tissue-specific (whole blood cell) of the correlated gene. Subnetwork 1 contains 1 seed, 99 nodes, and 100 edges. On the other hand, subnetwork 2 contains 1 seed, 21 nodes, and 22 edges. TCSBN database has been used for the analysis.

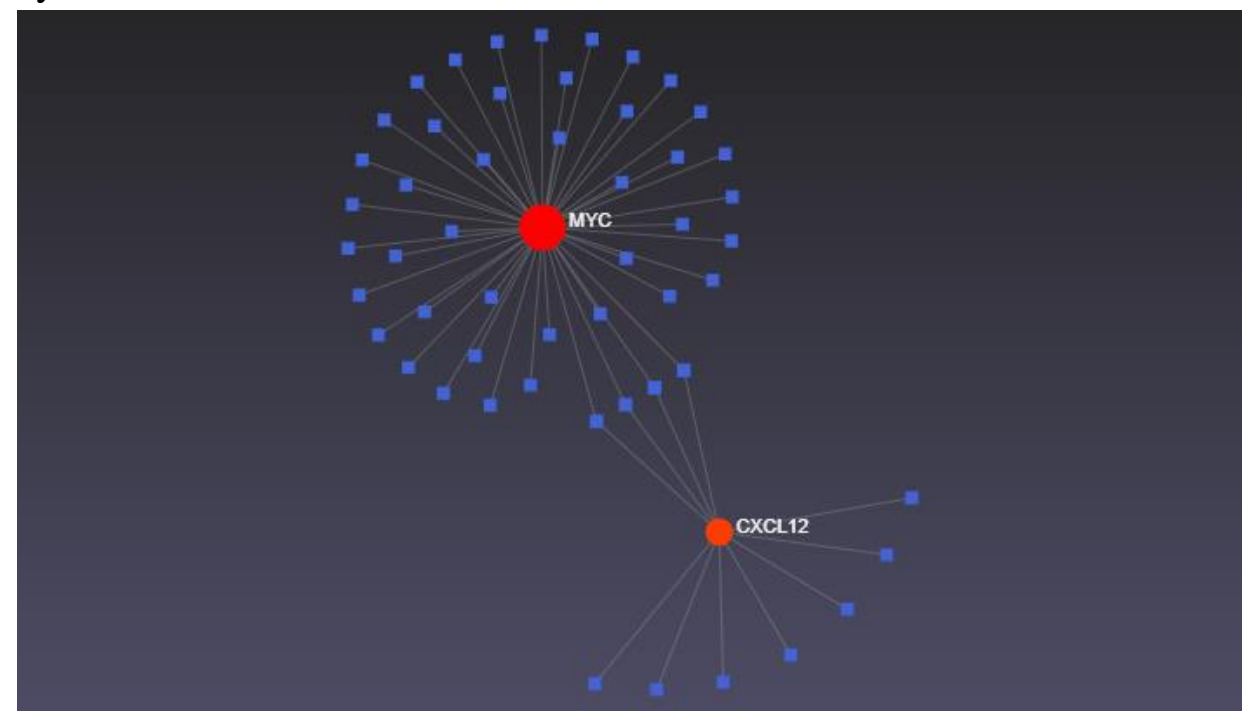

Figure 11. Gene disease interaction network (Subnetwork 1). 


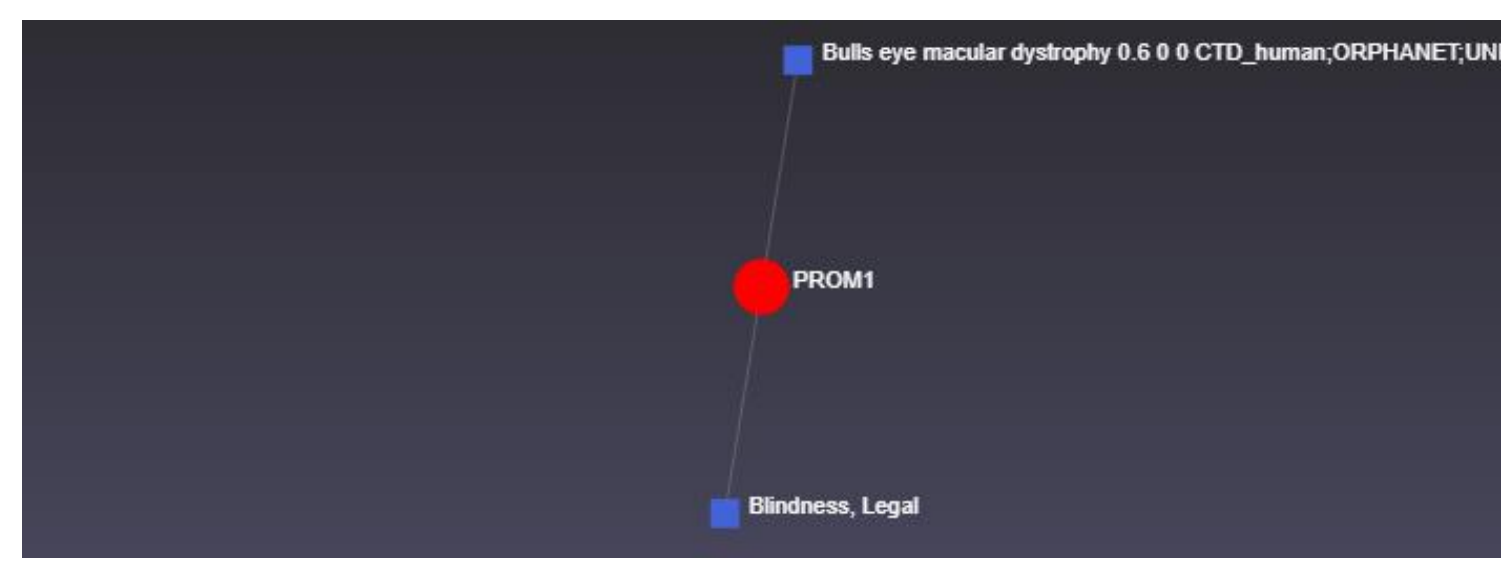

Figure 12. Gene disease interaction network (Subnetwork 2).

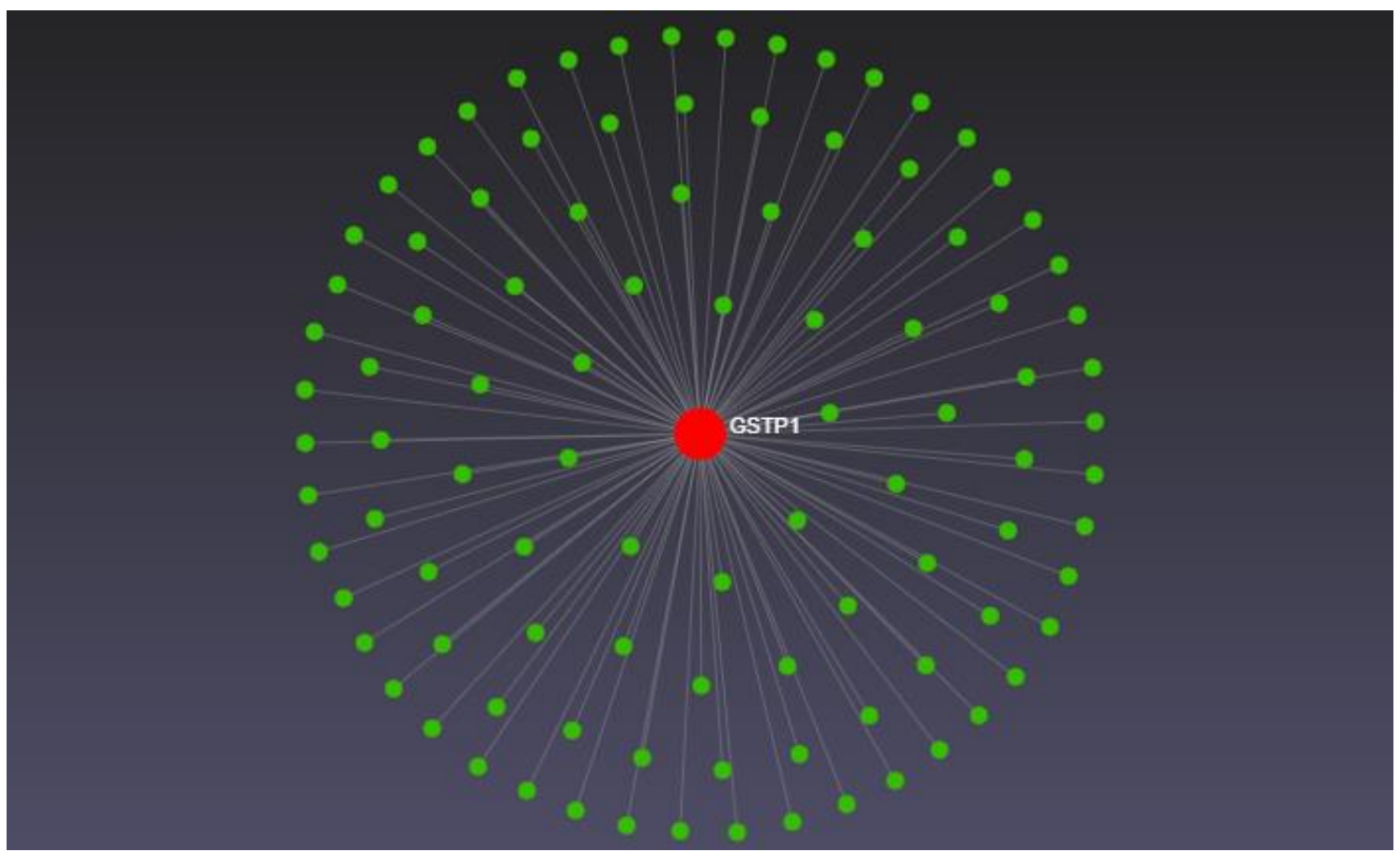

Figure 13. Tissue-specific co-expression network (subnetwork 1).

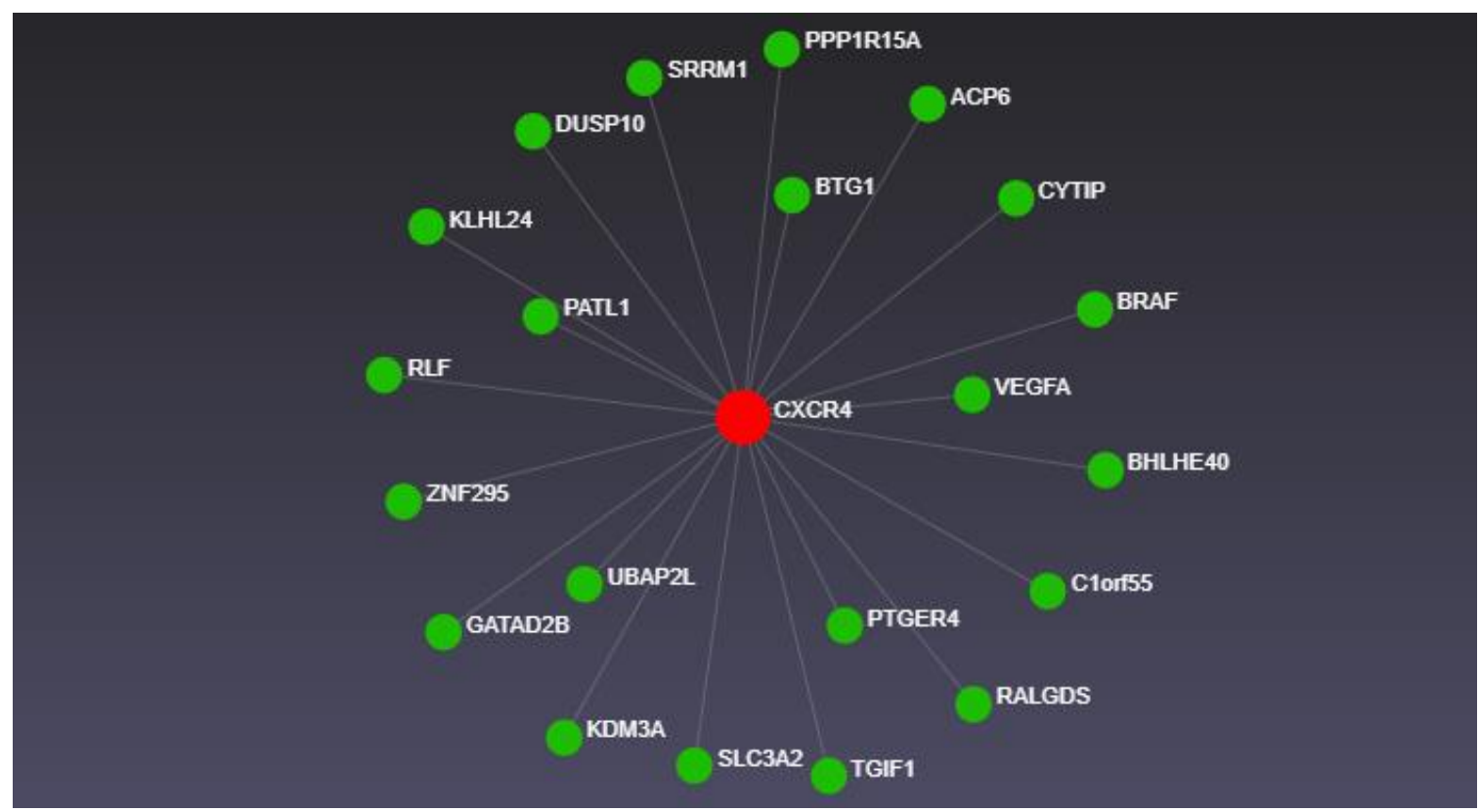

Figure 14. Tissue-specific co-expression network (subnetwork 1). 


\subsection{String network analysis.}

String analysis has been done among the common 8 genes of associated disease. KMeans clustering algorithm with cluster no 3 has been applied on the gene correlation shown in Figure 15. 8 genes have been clustered, which shows into 3 different groups green (GSTM1, GSTP1), red (TERT, MYC, PROM1), and blue (CXCR4, CXCL12) . Glass ball effect of stringing analysis shows the protein structures in the genes.

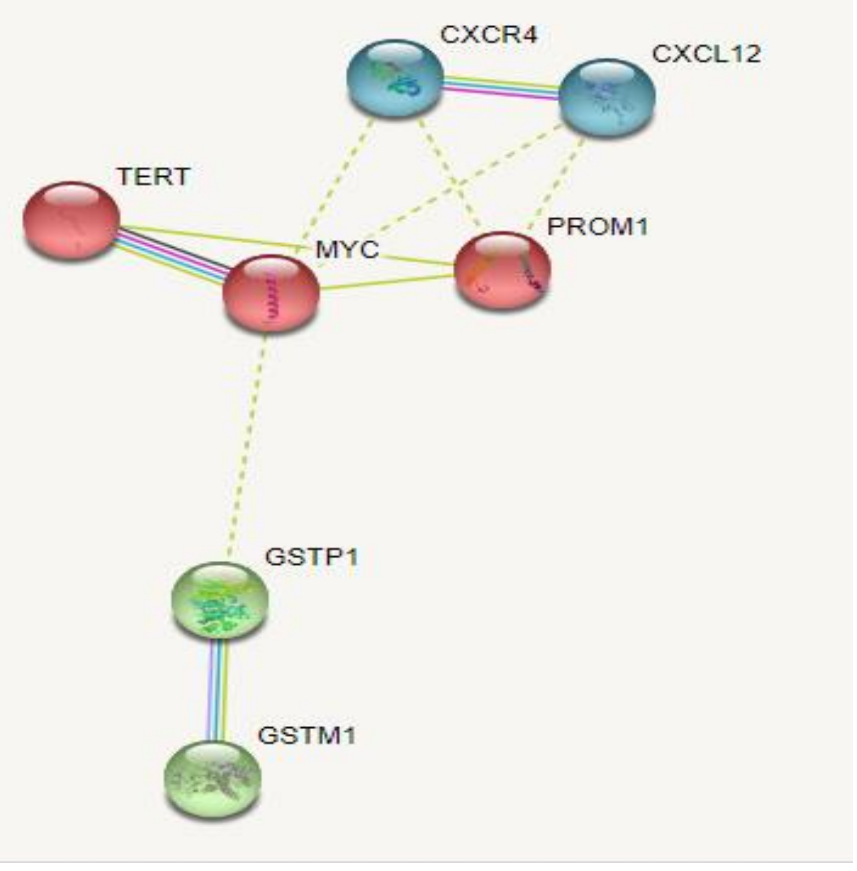

Figure 15. String analysis using K-means clustering algorithm.

\section{Conclusions}

The bioinformatics investigation was used to categorize collective genes from five dissimilar relative diseases, which will help categorize potential drugs for drug design and discovery processes. In the process, the number of genes was reduced and preprocessed which helped to find the exact genes significant for BC, ML, BDC, BT, and GM. The research determined 8 genes (TERT, MYC, GSTP1, GSTM1, CXCR4, CXCL12, GSTT1, PROM1) common among all the five diseases. To reveal protein-drug, protein-chemical, gene-disease interactions effectively, PPI, GRN, and TGI analyses have been done. From the PPI network, the hub proteins were selected. The research illustrated the common genes and their association and network profile, which will help us find candidate drugs as well as association with other genes.

\section{Funding}

This research received no external funding.

\section{Acknowledgments}

The authors are grateful who have participated in this research work.

\section{Conflicts of Interest}

The authors declare no conflict of interest. 


\section{References}

1. Abdelaziz Ismael, S.A.; Mohammed, A.; Hefny, H. An enhanced deep learning approach for brain cancer MRI images classification using residual networks. Artif. Intell. Med. 2020, 102, 101779, https://doi.org/10.1016/j.artmed.2019.101779.

2. Tandel, G.S.; Biswas, M.; Kakde, O.G.; Tiwari, A.; Suri, H.S.; Turk, M.; Laird, J.R.; Asare, C.K.; Ankrah, A.A.; Khanna, N.N.; Madhusudhan, B.K.; Saba, L.; Suri, J.S. A Review on a Deep Learning Perspective in Brain Cancer Classification. Cancers 2019, 11, 111, https://doi.org/10.3390/cancers11010111.

3. Carr, S.; Smith, C.; Wernberg, J. Epidemiology and Risk Factors of Melanoma. Surg. Clin. North Am. 2020, 100, 1-12, https://doi.org/10.1016/j.suc.2019.09.005.

4. Wouters, J.; Kalender-Atak, Z.; Minnoye, L.; Spanier, K.I.; De Waegeneer, M.; Bravo González-Blas, C.; Mauduit, D.; Davie, K.; Hulselmans, G.; Najem, A.; Dewaele, M.; Pedri, D.; Rambow, F.; Makhzami, S.; Christiaens, V.; Ceyssens, F.; Ghanem, G.; Marine, J.-C.; Poovathingal, S.; Aerts, S. Robust gene expression programs underlie recurrent cell states and phenotype switching in melanoma. Nat. Cell Biol. 2020, 22, 986998, https://doi.org/10.1038/s41556-020-0547-3.

5. Shain, A.H.; Bagger, M.M.; Yu, R.; Chang, D.; Liu, S.; Vemula, S.; Weier, J.F.; Wadt, K.; Heegaard, S.; Bastian, B.C.; Kiilgaard, J.F. The genetic evolution of metastatic uveal melanoma. Nat. Genet. 2019, 51, 1123-1130, https://doi.org/10.1038/s41588-019-0440-9.

6. Patel, V.G.; Oh, W.K.; Galsky, M.D. Treatment of muscle-invasive and advanced bladder cancer in 2020. CA Cancer J. Clin. 2020, 70, 404-423, https://doi.org/10.3322/caac.21631.

7. Richters, A.; Aben, K.K.H.; Kiemeney, L.A.L.M. The global burden of urinary bladder cancer: an update. World J. Urol. 2020, 38, 1895-1904, https://doi.org/10.1007/s00345-019-02984-4.

8. Witlox, W.J.A.; van Osch, F.H.M.; Brinkman, M.; Jochems, S.; Goossens, M.E.; Weiderpass, E.; White, E.; van den Brandt, P.A.; Giles, G.G.; Milne, R.L.; Huybrechts, I.; Adami, H.-O.; Bueno-de-Mesquita, B.; Wesselius, A.; Zeegers, M.P. An inverse association between the Mediterranean diet and bladder cancer risk: a pooled analysis of 13 cohort studies. Eur. J. Nutr. 2020, 59, 287-296, https://doi.org/10.1007/s00394-01901907-8.

9. Turner, M.C.; Gracia-Lavedan, E.; Cirac, M.; Castaño-Vinyals, G.; Malats, N.; Tardon, A.; Garcia-Closas, R.; Serra, C.; Carrato, A.; Jones, R.R.; Rothman, N.; Silverman, D.T.; Kogevinas, M. Ambient air pollution and incident bladder cancer risk: Updated analysis of the Spanish Bladder Cancer Study. Int. J. Cancer 2019, 145, 894-900, https://doi.org/10.1002/ijc.32136.

10. Alsaggaf, R.; St. George, D.M.M.; Zhan, M.; Pfeiffer, R.M.; Wang, Y.; Anderson, L.A.; Liu, Z.; Koshiol, J.; Bauer, A.J.; Wagner, K.R.; Greene, M.H.; Amr, S.; Gadalla, S.M. Benign tumors in myotonic dystrophy type I target disease-related cancer sites. Annals of Clinical and Translational Neurology 2019, 6, 1510-1518, https://doi.org/10.1002/acn3.50856.

11. Chiesa-Estomba, C.M.; Sistiaga-Suarez, J.A.; González-García, J.Á.; Larruscain, E.; Cammaroto, G.; MayoYánez, M.; Lechien, J.R.; Calvo-Henríquez, C.; Altuna, X.; Medela, A. Artificial Neural Network as a Tool to Predict Facial Nerve Palsy in Parotid Gland Surgery for Benign Tumors. Medical Sciences 2020, 8, 42, https://doi.org/10.3390/medsci8040042.

12. Grabowski, M.M.; Sankey, E.W.; Ryan, K.J.; Chongsathidkiet, P.; Lorrey, S.J.; Wilkinson, D.S.; Fecci, P.E. Immune suppression in gliomas. J. Neurooncol. 2020, https://doi.org/10.1007/s11060-020-03483-y.

13. Rajasurya, V.; Gunasekaran, K.; Surani, S. Interstitial lung disease and diabetes. World J. Diabetes 2020, 11, 351, https://doi.org/10.4239/wjd.v11.i8.351.

14. Barnes, D.R.; Rookus, M.A.; McGuffog, L.; Leslie, G.; Mooij, T.M.; Dennis, J.; Mavaddat, N.; Adlard, J.; Ahmed, M.; Aittomäki, K.; Andrieu, N.; Andrulis, I.L.; Arnold, N.; Arun, B.K.; Azzollini, J.; Balmaña, J.; Barkardottir, R.B.; Barrowdale, D.; Benitez, J.; Berthet, P.; Białkowska, K.; Blanco, A.M.; Blok, M.J.; Bonanni, B.; Boonen, S.E.; Borg, Å; Bozsik, A.; Bradbury, A.R.; Brennan, P.; Brewer, C.; Brunet, J.; Buys, S.S.; Caldés, T.; Caligo, M.A.; Campbell, I.; Christensen, L.L.; Chung, W.K.; Claes, K.B.M.; Colas, C.; Berthet, P.; Colas, C.; Collonge-Rame, M.-A.; Delnatte, C.; Faivre, L.; Giraud, S.; Lasset, C.; Mari, V.; Mebirouk, N.; Mouret-Fourme, E.; Schuster, H.; Stoppa-Lyonnet, D.; Adlard, J.; Ahmed, M.; Antoniou, A.; Barrowdale, D.; Brennan, P.; Brewer, C.; Cook, J.; Davidson, R.; Easton, D.; Eeles, R.; Evans, D.G.; Frost, D.; Hanson, H.; Izatt, L.; Ong, K.-r.; Side, L.; O’Shaughnessy-Kirwan, A.; Tischkowitz, M.; Walker, L.; Collonge-Rame, M.-A.; Cook, J.; Daly, M.B.; Davidson, R.; de la Hoya, M.; de Putter, R.; Delnatte, C.; Devilee, P.; Diez, O.; Ding, Y.C.; Domchek, S.M.; Dorfling, C.M.; Dumont, M.; Eeles, R.; Ejlertsen, B.; Engel, C.; Evans, D.G.; Faivre, L.; Foretova, L.; Fostira, F.; Friedlander, M.; Friedman, E.; Frost, D.; Ganz, 
P.A.; Garber, J.; Gehrig, A.; Gerdes, A.-M.; Gesta, P.; Giraud, S.; Glendon, G.; Godwin, A.K.; Goldgar, D.E.; González-Neira, A.; Greene, M.H.; Gschwantler-Kaulich, D.; Hahnen, E.; Hamann, U.; Hanson, H.; Hentschel, J.; Hogervorst, F.B.L.; Hooning, M.J.; Horvath, J.; Hu, C.; Hulick, P.J.; Imyanitov, E.N.; Chenevix-Trench, G.; Phillips, K.-A.; Spurdle, A.; Blok, M.; Devilee, P.; Hogervorst, F.; Hooning, M.; Koudijs, M.; Mensenkamp, A.; Meijers-Heijboer, H.; Rookus, M.; Engelen, K.v.; Andrieu, N.; Noguès, C.; Isaacs, C.; Izatt, L.; Izquierdo, A.; Jakubowska, A.; James, P.A.; Janavicius, R.; John, E.M.; Joseph, V.; Karlan, B.Y.; Kast, K.; Koudijs, M.; Kruse, T.A.; Kwong, A.; Laitman, Y.; Lasset, C.; Lazaro, C.; Lester, J.; Lesueur, F.; Liljegren, A.; Loud, J.T.; Lubiński, J.; Mai, P.L.; Manoukian, S.; Mari, V.; Mebirouk, N.; Meijers-Heijboer, H.E.J.; Meindl, A.; Mensenkamp, A.R.; Miller, A.; Montagna, M.; Mouret-Fourme, E.; Mukherjee, S.; Mulligan, A.M.; Nathanson, K.L.; Neuhausen, S.L.; Nevanlinna, H.; Niederacher, D.; Nielsen, F.C.; Nikitina-Zake, L.; Noguès, C.; Olah, E.; Olopade, O.I.; Ong, K.-r.; O’Shaughnessy-Kirwan, A.; Osorio, A.; Ott, C.-E.; Papi, L.; Park, S.K.; Parsons, M.T.; Pedersen, I.S.; Peissel, B.; Peixoto, A.; Peterlongo, P.; Pfeiler, G.; Phillips, K.-A.; Prajzendanc, K.; Pujana, M.A.; Radice, P.; Ramser, J.; Ramus, S.J.; Rantala, J.; Rennert, G.; Risch, H.A.; Robson, M.; Rønlund, K.; Salani, R.; Schuster, H.; Senter, L.; Shah, P.D.; Sharma, P.; Side, L.E.; Singer, C.F.; Slavin, T.P.; Soucy, P.; Southey, M.C.; Spurdle, A.B.; Steinemann, D.; Steinsnyder, Z.; Stoppa-Lyonnet, D.; Sutter, C.; Tan, Y.Y.; Teixeira, M.R.; Teo, S.H.; Thull, D.L.; Tischkowitz, M.; Tognazzo, S.; Toland, A.E.; Trainer, A.H.; Tung, N.; van Engelen, K.; van Rensburg, E.J.; Vega, A.; Vierstraete, J.; Wagner, G.; Walker, L.; Wang-Gohrke, S.; Wappenschmidt, B.; Weitzel, J.N.; Yadav, S.; Yang, X.; Yannoukakos, D.; Zimbalatti, D.; Offit, K.; Thomassen, M.; Couch, F.J.; Schmutzler, R.K.; Simard, J.; Easton, D.F.; Chenevix-Trench, G.; Antoniou, A.C.; Collaborators, G.S.; Collaborators, E.; kConFab, I.; Investigators, H.; Investigators, G.; on behalf of the Consortium of Investigators of Modifiers of, B.; Brca. Polygenic risk scores and breast and epithelial ovarian cancer risks for carriers of BRCA1 and BRCA2 pathogenic variants. Genet. Med. 2020, 22, 1653-1666, https://doi.org/10.1038/s41436-020-0862-x.

15. Islam, S.; Rehana, H.; Asaduzzaman, S.; Hossen, S.M.; Hossain, R.; Bhuiyan, T.; Uddin, M.S.; Akter, N. Automated Risk Prediction by Measuring Pneumothorax Size using Deep Learning. In Proceedings of 2020 IEEE Region 10 Symposium (TENSYMP), 5-7 June 2020; 1747-1751.

16. Banu, B.; Asaduzzaman, S.; Akter, N.; Hossain, S.M.; Bhuiyan, T. Concurrent Field Practice Act as an Efficient Teaching Pedagogy to Originate Public Health Professionals: A Bangladesh Context. Universal Journal of Public Health 2020. https://doi.org/10.13189/ujph.2020.080401.

17. Islam, M.R.; Ahmed, M.L.; Kumar Paul, B.; Asaduzzaman, S.; Ahmed, K. Common Gene Regulatory Network for Anxiety Disorder Using Cytoscape: Detection and Analysis. In Proceedings of Bioinformatics and Biomedical Engineering, Cham, 2019; 209-218. 